\title{
Editorial: Torpedoes and Rockets
}

This issue has as its central theme 'extreme performance', looking at those stocks which by their omission or inclusion can destroy or make a manager's performance. After the roller coaster ride of the last couple of years, this is extremely topical. The extraordinary volatility of individual stocks, industries and stocks within industries has undermined traditional risk models and made investing more than the usual lottery.

One response to this has been to index portfolios and so apparently to eliminate this risk. The reality though is that indexing does not necessarily make portfolios immune to the effects of volatility. In the first quarter of 2000 , at the very peak of the technology bubble, we saw the reconstruction of the FTSE 100 index load up on high tech stocks, while eliminating old world favourites such as Whitbread. Within six months, many of these additions and deletions to the index were reversed. A similar story happened in other indices such as the Topix. A manager slavishly following the FTSE might show low tracking error but at a considerable cost to real wealth.

This editorial picks up on this theme and asks some basic questions on indexation and concludes that it is ...

\section{Time to stop indexing: time to go passive!}

It is nearly four decades since Bill Sharpe's capital asset pricing model
(CAPM). We think it is time to take his work seriously, and, if we do so, we conclude that we need to change many of our cherished beliefs and radically restructure our portfolios. There are two striking conclusions. First, we should exclude all references to asset categories such as emerging/developed markets, domestic/international, country, sector, industry and capitalisation. Secondly, indexing strategies have come a long way from the concepts behind CAPM. We need to get back to basics and stop passively managing to the active stock selection decisions of the index committees.

These recommendations simply rest on the basic beliefs behind CAPM that investors are rational, risk averse and do not make persistent mistakes in their efforts to maximise utility. Indeed, it is difficult to refute this idea without resorting to controlled experiments that focus on idiosyncratic behaviour. This basic belief in investor rationality, together with the assumptions that investors are price-takers in frictionless markets and have the same time horizon and expectations, leads us directly to the well-known and compelling CAPM conclusion that holding the market portfolio will maximise your expected (risk-adjusted) return.

Implicit is the belief that prices appropriately reflect rational investor expectations about the return and risk of assets. Benchmark approaches that employ asset categories such as 
domestic/international are essentially proposing an asset pricing model that suggests market prices are not in equilibrium. We view these approaches as an inefficient form of active management and feel they should not form the basis of strategic investment strategy.

Further, it is time to stress that, in implementation, investors should recognise the difference between passive investing and indexing. True passive investors aim to capture the returns associated with a broad market portfolio rather than blindly follow an index provider's particular approximation of the market portfolio. From 1990 to 1999, there were 195 additions to the S\&P500 Index, the benchmark with more money tracking it than any other and where tracking errors from indexed funds are measured by just a couple of basis points. To achieve that kind of tracking, managers must trade close to the time when stocks enter or leave the index. From pre-announcement to effective date, the average rise in price relative to the index was +7.5 per cent and the 'permanent' price effect on joining the index is about +3.5 per cent. The cost to funds in terms of geometric mean return to minimise tracking error is considerable. This has nothing whatsoever to do with building wealth or with the principles behind CAPM.

These conclusions are uncontroversial if you believe in CAPM, yet few, if any portfolios adhere to these principles today. It would be reassuring if we could believe that the reason why portfolios are not structured this way was because the argument had moved on, perhaps to some general, rather than partial equilibrium model with radically different properties. Sadly this is not the case. Instead, inertia and peer group pressure are probably behind the industry's failure to follow these principles.

Those who do challenge the CAPM conclusion that the market portfolio is the unique efficient portfolio often assert that the assumptions underlying the theory are unrealistic. Our view is that while the CAPM is an abstraction of reality, its assumptions are reasonable, and its conclusions are profound and difficult to challenge. Since our primary goal is to create an appropriate global strategic (or passive) equity strategy, challenging the simplifying assumptions of the CAPM gets us no closer to a solution. A valid challenge would be to propose an alternative general model of asset pricing that leads to clearly different investment policy conclusions. We have not seen any such alternative.

If we consider more pragmatic issues regarding the ideal strategic portfolio, happily we find that the CAPM-inspired market portfolio approach also has distinct cost advantages. A CAPM-based strategy meets the requirements of:

1. performance: it is a strategy designed to earn 'top' long-term returns

2. stability: it is a strategy that can be sustained indefinitely at low cost.

Although we argue that the industry needs to move away from slavishly following every index change, we do acknowledge the need for some reference benchmark. Here we believe there is good news as all index providers are making sensible improvements to their benchmarks. What then are the right attributes for strategic benchmarks?

A desirable attribute of a strategic benchmark is that it exhibit macroconsistency. This means that a 'good' benchmark is one where the relative prices of securities would be unchanged, even if everyone decided to hold the benchmark. Put another way, macroconsistency essentially ensures that the strategic benchmark represents an equilibrium solution. Capitalisation- 
weighted benchmarks are generally macroconsistent, provided they are free-float adjusted.

\section{The argument against asset categorisation}

We have so far made no reference to commonly used asset categories such as emerging/developed markets, countries, sectors, industries, size or type (multinational/local) of firm. This omission is intentional and represents the implicit CAPM belief that over time rational, profit-motivated investors price assets, and asset categories, to appropriately reflect return and risk expectations.

Asset categorisation almost invariably involves arbitrary distinctions. This contrasts sharply with a capitalisationweighted approach, which maintains the desired weight of each asset category by automatically incorporating investor expectations, through price. We believe that asset categories should be used to allocate capital in an equity strategy only to the extent that an investor's theory of how assets are priced requires such a categorisation.

Alternatives to our capitalisationweighted approach are often based on the belief that assets are mispriced by the markets. This belief typically manifests itself as a concern that prices, and therefore capitalisation, for a particular asset category are too high. (It is interesting to note that it is rarely the belief that prices and capitalisation are too low that generates concern about mispricing.) Concerns about over-pricing have been raised about any number of different asset categories. Examples of allegedly mispriced assets include Japanese equities, Internet firms, Mexican equities, telecom firms and even global equities as a whole.

Benchmark responses to such pricing concerns are implemented in a number of ways: from ad hoc weight limits aimed at reducing exposure to specific assets, to more complex GDP-weighted approaches to country allocation. We find, however, that most of these efforts are, in effect, asset pricing models that find fault with the prices investors have set in markets. The asset pricing models that underlie these non-capitalisationweighted approaches range from individually held beliefs about asset category valuation, to posited relationships between the size of economies and the size of equity markets.

We can understand the desire to avoid establishing too large a position in expensive assets. Investors, however, should be aware of the substantial pitfalls associated with abandoning an approach based on a well-reasoned general model of equilibrium asset pricing, in favour of an asset pricing model that presumes the market is in disequilibrium but will eventually agree with the posited model.

Asset 'mispricing' is easily identified after the event. With the benefit of hindsight, it is straightforward to suggest an asset pricing model that avoids or mitigates an unpleasant return experienced by an asset category. However, it is anything but straightforward to recognise:

1. when, on a forward-looking basis, the collective forecast of market participants is incorrect

2. when prices will reflect the forecast.

Also, costs associated with non-capitalisation-weighted approaches can be significant. Changes in the spread between the market's forecast of return and the implied forecast of the suggested model lead to portfolio turnover and transaction costs. These costs represent a real hurdle to the active approach that is 
implied in a non-capitalisation-weighted strategy.

Of course adopting a global cap-weighted benchmark with no domestic, home country bias would lead, for most countries, to a very low weight to domestic equities and a very high exposure to foreign currencies. Our view on currency in a global strategic context is that changes in spot rates represent uncompensated portfolio volatility. Without the benefit of a positive expected return, unhedged currency exposure increases the risk that liabilities will not be met (we assume liabilities are ultimately a local-currency-denominated consumption basket). These beliefs lead us to the conclusion that currency exposure is best hedged back to the currency associated with the ultimate consumption basket.

We are sensitive to the fact that our conclusions rest on both a simplifying assumption regarding the currency exposure of the consumption basket (it could be a multi-currency consumption basket), and the implicit assumption that the risk reduction associated with hedging dominates any potential diversification benefit of maintaining unhedged currency exposures. We think both assumptions are reasonable, however, and represent the logical default position for determining the appropriate benchmark currency hedging policy.

Of course, this basic position on currency hedging assumes an investor can eliminate currency volatility without cost. Unfortunately, as we all know, there are both explicit and implicit costs associated with currency hedging. Explicit costs include those associated with spot transactions and the cost of carry associated with forward contracts. Implicit costs include cash flow volatility-induced transaction costs, transaction costs induced by volatility in underlying currency exposures and counter party risk.
From the perspective of building a global, passive benchmark, we interpret the costs associated with currency hedging as a modest positive expected return to remaining unhedged. Because the volatility associated with this expected return is much higher than market risk premiums warrant, our basic recommendation to hedge currency exposures back to the currency of the ultimate consumption basket is unaffected, although the optimum degree of hedging is likely to be less than 100 per cent.

\section{Implementing the world market portfolio}

Capturing the return of the market portfolio of investable wealth-generating assets is best viewed as a continuous process, where income and inflows provide the means to respond patiently to the subtle changes in capitalisation arising primarily from firms' financing decisions. One of the under-appreciated benefits of this approach to investing is the extent to which it is self-rebalancing, and therefore minimises transaction costs. This observation is particularly true for a global capitalisation-weighted approach, as it avoids the constant rebalancing that accompanies non-capitalisation-weighted approaches employing size, sector, country, region or 'state of development' as criteria for the allocation of capital. Non-capitalisation-weighted approaches often result in rebalancing in response to activity that is unrelated to the ideas that form the basis of the approach.

Cross-border mergers and reclassification of countries as emerging or developed are good examples of activity that can generate rebalancing unrelated to the thesis underlying the benchmark.

The Vodafone/Mannesman acquisition highlighted one of the absurdities that can result. As Vodafone acquired Mannesman, Mannesman's capitalisation 
'migrated' from Germany to the UK. As UK institutional funds have a large domestic bias, managers 'had to' increase their weight to Vodafone. On the other hand, if Mannesman had acquired Vodafone, the reverse would have been true, and yet the business of Vodafone/Mannesman and all of its cash flows would have been exactly the same irrespective of whether it was listed in Frankfurt or London.

While a global capitalisation-weighted approach has clear advantages in terms of minimising costs, it is nonetheless important to recognise the difference between passive investing and indexing. True passive investors aim to capture the returns associated with a broad market portfolio rather than blindly following an index provider's particular approximation of the market portfolio. To that end, we suggest that investors avoid making continuous transactions in an attempt to track a specific benchmark as closely as possible. Instead, we suggest that investors resist selling securities, and simply add to under-weighted positions as cash flows and liquidity provide the opportunity. More generally, investors should avoid participating in unnatural demand for liquidity, such as index changes and float adjustments, and should be willing to provide liquidity if doing so reduces costs and is consistent with the underlying investment objective.

Investors should take all reasonable steps to acquire and maintain desired exposures at minimum cost (eg using crossing networks, futures and swaps). In essence, we are saying that an obsessive interest in minimising tracking error against what is inevitably an arbitrary view of the market portfolio, will incur costs that harm the much more important long-run geometric return. While there should be a target reference portfolio, wherever possible transactions should only be undertaken when either cash flow needs mandate a transaction, or when the fund can be a provider, rather than a taker, of liquidity (ie engage in a free cross).

Today's indexing approach does lead itself to one, very simple, performance metric, tracking error. What we propose will involve more complicated metrics, and an increase in the oversight or governance 'budget'. As well as tracking to a reference benchmark, managers and their clients will need to review turnover, transaction costs and measures to demonstrate the breadth of holdings the manager has acquired in the market portfolio.

\section{Conclusion}

In one sense, we are saying nothing new and are merely reiterating CAPM's basic message from 1964. We believe, however, there are many issues in evidence today that make it important to reconsider the CAPM message in the current context. These issues include:

- the continuing worldwide tendency to home bias

- stock concentration, particularly outside the US

- the increasingly disruptive and costly effects of index rebalancing

— the increasingly arbitrary definitions being employed by investors (multinational, developed, developed-emerging, emerging and pre-emerging)

- the decreasing importance of countries and regions (the conventional equity asset class differentiators) in explaining stock returns.

Our simple message is that the original ideas underlying CAPM were largely right, and no better equilibrium asset pricing model has emerged since. Following CAPM in our globalised 
world means abandoning notions such as 'domestic vs international' and 'developed vs emerging'.

We would do better to follow the CAPM approach through 'passive' management of a global market portfolio, rather than adopt an 'index' management approach.
We should keep the establishment of a strategic benchmark separate from active investment decisions.

Alan J. Brown Group Chief Investment Officer \& Chairman State Street Global Advisors UK Limited 